\title{
DEGRADATION OF POLYPROPYLENE IN NATURALLY AND ARTIFICIALLY WEATHERED PLASTIC MATRIX COMPOSITES
}

\author{
James S. Fabiyi ${ }^{1,2}$, Armando G. McDonald ${ }^{1, \star}$
}

\begin{abstract}
Effects of accelerated and natural weathering on the molecular weight distribution (MWD) and crystallinity of polypropylene (PP) in wood plastic composites (WPC) were investigated. The composites were produced from pine fibers $(60 \%)$ and PP $(40 \%)$. Prolonged weathering caused an increase in wood degradation and erosion thereby leaving cracks and "pits" on the surface. Pyrolysis gas chromatography-mass spectrometry (Py GC-MS) revealed that PP dominated the weathered surface due to wood degradation. For matrix analysis, PP was extracted using 1,2,4-trichlorobenzene. Crystallinity and molecular weight distribution of PP were monitored by differential scanning calorimetry (DSC) and gel permeation chromatography (GPC), respectively. PP's crystallinity increased upon longer exposure time. The weight and number average molecular weight $\left(M_{w}\right.$ and $\left.M_{n}\right)$ decreased with an increase in weathering duration. An increased polydispersity $\left(\mathrm{PD}=M_{w} / M_{n}\right)$ implies that a secondary cross-linking process occurred during weathering.
\end{abstract}

Keywords: Crystallinity, molecular weight distribution, polypropylene, weathering, wood plastic composites

\section{INTRODUCTION}

Wood plastic composites (WPC) are a group of plastic matrix composites made from a combination of wood fiber (or natural fiber) and a thermoplastic resin, together with varying amounts of additives. WPC have been used in various interior and exterior applications like deck floors, railings, fences, landscaping timbers, cladding and siding, park benches, molding and trim, window and door frames, and indoor furniture (Clemons 2002, Smith and Wolcott 2006). The growth in exterior WPC applications has resulted in concerns about their long-term weatherability and durability. Klyosov (2006) reported that one of the major USA based WPC manufacturers received 466 warranty claims relating to its decking products manufactured in 2002 and 2003 due to its crumbling, degradation, and failure. Consideration of the performance of a composite material in its end-use environment is a very significant task. Therefore, several studies have been conducted on degradation of WPC, which includes biodegradation (fungi and bacteria) (Schauwecker et al. 2006, Fabiyi et al. 2011), mechanical degradation (Stark et al. 2004) and photodegradation (Stark et al. 2004, Stark and Matuana 2004). However, among these degradation types, photodegradation is more pronounced, especially in the presence of moisture (Stark and Matuana 2004).

\footnotetext{
${ }^{1}$ Renewable Materials Program, Department of Forest, Rangeland and Fire Sciences, University of Idaho, Moscow, ID 83844-1132, USA ${ }^{2}$ Present address: Department of Forestry and Wood Technology, The Federal University of Technology, P.M.B 704, Akure, Nigeria •Corresponding author: armandm@uidaho.edu Received: 12.08. 2013 Accepted: 29.09. 2013.
} 
The effects of weathering (photodegradation) on the mechanical, aesthetic and chemical properties of WPC have been studied (Stark et al. 2004, Stark and Matuana 2004, Falk et al. 2000, Lundin 2001). Stark et al. (2004) reported that photodegradation caused mechanical properties reduction of HDPE-pine composites; this was reported to be due to moisture that caused moisture-induced interfacial cracks. Also, the flexural modulus of elasticity (MOE) of $50 \%$ wood flour filled HDPE decreased by $35 \%$ during the first $1000 \mathrm{~h}$ of exposure time of a $2000 \mathrm{~h}$ xenon-arc weathering trial (Lundin 2001). Falk et al. (2000) reported that color change and reduced $\mathrm{MOE}$ and flexural modulus of rupture (MOR) occurred during weathering of HDPE and PP based WPC.

The behavior of the wood component of the WPC to weathering using pyrolysis-gas chromatographymass spectrometry and FTIR spectroscopy has been reported (Fabiyi et al. 2008, Fabiyi and McDonald 2009). The outcomes of these researchers revealed that wood content decreased with prolonged exposure of WPC to weathering. In addition, the photodegradation of lignin (in wood as revealed by pyrolysis-gas chromatography-mass spectrometry data) resulting in quinones and methyl-hydroquinone formation was attributed to be one of the contributors to the HDPE and PP based WPC surface color change (Fabiyi et al. 2008). Fabiyi et al. (2009) reported influence of weathering on the HDPE matrix of modified wood based WPC. Unfortunately, extensive studies concerning the effects of weathering on the properties (molecular weight distribution (MWD) and crystallinity) of PP matrix extracted from the weathered WPC are not readily available. Even though PP was the first synthetic polymer to achieve industrial importance and widely applied because of its low production cost, easy processability and excellent mechanical properties (Azuma et al. 2009), its behaviour during weathering of WPC has not been reported. Therefore, an in-depth understanding of the behavior of plastic matrix in WPC during weathering is very important for assessing service life.

The determination of MWD and crystallinity of PP could provide useful information to understand the contributions of plastic matrix to the WPC properties during weathering and help explain the interfacial cracks induced by moisture as observed by Stark et al. (2004). These macromolecular properties could also enhance our understanding about the plastic recycling ability. Polymer physical properties are extremely sensitive to MWD and molecular architectures, and therefore chain scission and cross-linking reactions have an important effect on polymer performance (Chiantore et al. 2001). It is crucial to know that molecular changes that occur during weathering affect the overall properties of the polymer including melt flow/viscosity (an important factor to be considered in case of plastic recycling), molecular weight, and mechanical strength (Philip et al. 2004). Philip et al. (2004) also stated that reduction in molecular weight (chain scission) leads to shorter polymer chains and decreases almost all mechanical properties. Torikai et al. (1990) investigated the photodegradation of non-reinforced polyethylene and concluded that crystallinity is one of the important factors in photostability. Changes in the degree of crystallinity have been shown to have a pronounced effect on the mechanical behavior and fracture toughness of a polymer. Degree of crystallinity of polymer is a key variable in defining the morphological, physical, and mechanical properties of the polymer (Isasi et al. 1999). This is due to the crystallites acting as points of reinforcement and constraining the amorphous regions domains between crystallites (Hay 1995). Therefore, investigating the effect of weathering on the MWD and crystallinity of the plastic matrix is important for outdoor structural applications of WPC.

Therefore, the behavior of the in-situ PP is the target of this study. Additionally, the presence of wood constituent polymers would affect the values of polymer MWD and crystallinity of the PP. Hence, the need to extract the plastic matrix prior to analysis is a right step toward understanding the contribution of the PP to physical and mechanical property changes of weathered WPC. Also, the bahviour of in-situ wood component of the WPC would be monitored using pyrolysis gas chromatography coupled with mass spectroscopy (pyGC-MS). 
This study differed from previous published articles on WPC, particularly PP based natural fibers composites because it extensively elucidates the structural modifications at various scales (from molecular to macroscopic scale) by using four analytical methods: scanning electron microscopy (SEM), pyGCMS, gel permeation chromatography (GPC) and differential scanning calorimetry (DSC). The effects of weathering on the PP matrix and wood component of the WPC were thoroughly considered. This study did not attempt to correlate the different weathering regimes (unweathered, outside and xenon-arc). In addition, it did not correlate the relationship that might exist among the data collected by the four analytical methods. However, basic information on the water absorption and flexural testing properties was obtained for the unweathered samples.

Therefore, the aim of this study was to investigate the weathering behavior of the PP matrix and wood component in pine wood based composites by using microscopy, pyGC-MS, GPC and DSC. Additionally, the moisture and mechanical properties of unweathered WPC were determined.

\section{MATERIALS AND METHODS}

\section{Materials}

PP (Solvay Fortilene, HB 2300) and pine wood fiber (60-mesh, American Wood Fibers) were used for WPC production. One formulation based on $60 \%$ of wood and $40 \%$ of plastic was considered since interest is on the PP behavior. Materials were compounded and extruded on a $35 \mathrm{~mm}$ counter rotating conical twin-screw extruder (Cincinnati Milacron) to a profiled dimension of 9,5 $\mathrm{mm} \times 38 \mathrm{~mm}$. The barrel and die temperatures were set between 149 and $193^{\circ} \mathrm{C}$. The temperature settings of the seven heating zones from the intake of the barrel to the output of the die were set at 149, 165, 175, 183, 190, 193 and $193^{\circ} \mathrm{C}$. The extruded profiles were then knife milled (effect of milling was not taken into consideration because all the tested samples were surface milled; so no bias treatment occurred during the testing) to a thickness of 5,0 mm because many commercial WPC products are surface finished.

Samples for each weathering regime were randomly selected because the WPC produced were homogeneous (same raw materials - pine wood fiber and polypropylene - and processing temperatures). Similarly, samples for various analytical procedures were randomly removed from the xenon-arc weathering chamber and outside weathering site. The numbers of samples tested by each analytical instrument are stated under each section.

\section{Flexural properties and water absorption tests of unweathered WPC}

Three point flexural tests (modulus of rupture (MOR), modulus of elasticity (MOE)) were performed on the WPC $(20 \mathrm{~mm} \times 5,73 \mathrm{~mm} \times 115 \mathrm{~mm}, 7$ replicates $)$ in accordance with ASTM D 790-02 (2008) on an Instron 5500R-1137 universal test machine and data processed using Bluehill v2 software (Instron). Water absorption (WA) and thickness swell (TS) tests were conducted on the WPC ( $5 \mathrm{~mm} \times 20 \mathrm{~mm} \times$ $50 \mathrm{~mm}, 5$ replicates) following a modified ASTM D 570-98 procedure (2005). The WPC were immersed in water at $23^{\circ} \mathrm{C}$ for 28 days and periodically weighed. Weight gain and thickness swell were measured for determination of WA and TS, respectively. 


\section{Weathering of the WPC}

The accelerated weathering test was conducted in a xenon-arc weatherometer (Q-Sun) using WPC specimens $(5 \mathrm{~mm} \times 30 \mathrm{~mm} \times 101 \mathrm{~mm})$. The average irradiance was $0.70 \mathrm{~W} / \mathrm{m}^{2}$ at $340 \mathrm{~nm}$ wavelength with a chamber temperature of approximately $70^{\circ} \mathrm{C}$ with water spray. Tests were performed according to the ASTM D 6662 (2003); this is one of the procedures that encourage simulated severe weathering environment. The natural weathering test was conducted by exposing the WPC specimens $(5 \mathrm{~mm}$ $\times 30 \mathrm{~mm} \times 610 \mathrm{~mm}$ ) outside in Moscow, Idaho, USA on a south-facing wall at an angle of $45^{\circ}$ in accordance with ASTM D 1435 (2003). The average daylight in Moscow within the period of exposure was grouped into two: the first two month (August and September) has 12-14 h/day while the last two months (October and November) has 9-10 h/day. The latitude and longitude of Moscow are $46,4^{\circ} \mathrm{N}$ and $116,6^{\circ} \mathrm{W}$, respectively.

The minimum and maximum temperatures in Moscow within the 4 months of exposure were 1,2 and $28,9^{\circ} \mathrm{C}$, respectively. The annual average minimum and maximum temperatures are 2,2 and $14,7^{\circ} \mathrm{C}$, respectively. The total amount of yearly precipitation (rain and melted snow) is $68,8 \mathrm{~cm}$ (http:// www.currentresults.com/Weather/Idaho/average-yearly-precipitation.php). The sample condition was assessed after 0,200, 400, 800 and $1200 \mathrm{~h}$ of exposure in xenon-arc and after 0, 30, 60, 90 and 120 days of exposure in outside weathering regime.

\section{SEM analysis of WPC}

SE micrographs were obtained on a LEO Gemini field emission SEM instrument. Sections of unweathered and xenon-arc weathered WPCs were cut into approximately $8 \mathrm{~mm} \times 8 \mathrm{~mm}$ pieces. The specimens were mounted on aluminum stubs using carbon tape. The weathered surfaces were analyzed directly (without coating) at $1 \mathrm{kV}$ at a magnification of 70x. The SEM analysis of the outside weathered samples was not considered.

\section{PyGC-MS of WPC}

Wood derived compounds (lignin, hemicelluloses and cellulose) were identified and quantified by pyGC-MS as described in Fabiyi et al. 2008, Fabiyi and McDonald 2009). Two replicates specimens $(\sim 50 \mu \mathrm{g})$ obtained from the surface were pyrolyzed at $600^{\circ} \mathrm{C}$ in an SGE Pyrojector II (Ringwood, Australia) coupled to a GC-MS (PolarisQ, ThermoQuest) instrument. Volatile products were separated using a ZB-1 capillary column ( $30 \mathrm{~m}$ x $0.25 \mathrm{~mm}$, Phenomenex) using a temperature ramp from $40^{\circ} \mathrm{C}$ $(2 \mathrm{~min})$ to $300^{\circ} \mathrm{C}(10 \mathrm{~min})$ at $5^{\circ} \mathrm{C} / \mathrm{min}$. Wood content in the weathered WPC samples was quantified by developing a calibration curve from the total peak areas under the wood derived peaks relative to the total peak areas of the PP derived peaks. Calibration curves were based on tests of a series of WPC formulations of known wood content ranging from 0 to $100 \%$ in PP-based WPC.

\section{Polypropylene Extraction}

PP was extracted from the unweathered and weathered WPC. The WPC surface was cut with a razor blade and approximately $500 \mathrm{mg}$ of the material was weighed into a flat bottom flask and 1,2,4-trichlorobenzene (TCB) $(50 \mathrm{~mL})$ was added. The contents were then rapidly heated with a microwave oven (Sanyo, $600 \mathrm{~W}$ ) for $3 \mathrm{~min}$ to ensure complete solubilization but minimize oxidation. The solubilized PP was collected by separating wood fibers from the heated contents using a cotton wool filter, then re-filtered through filter paper (Whatman No.1) and dried under a stream of $\mathrm{N}_{2}$ to obtain a film of PP. The PP extracts were subsequently analyzed. 


\section{Differential Scanning Calorimetry}

DSC was performed on a TA2910 instrument to monitor the thermal behavior of PP crystallization according to ASTM D 3418 (1999). TCB extracted PP (5-7 mg) was analyzed using a temperature profile after 2 min equilibration at $70^{\circ} \mathrm{C}$, then ramped to $200^{\circ} \mathrm{C}$ at a heating rate of $10^{\circ} \mathrm{C} / \mathrm{min}$ and held isothermally for $10 \mathrm{~min}$, cooled to $70^{\circ} \mathrm{C}$ at $-10^{\circ} \mathrm{C} / \mathrm{min}$. Two replicate measurements were performed for each sample. The degree of crystallinity was calculated from the experimentally determined heat of fusion for the extracted PP and the heat of fusion $\left(\Delta H_{f}^{o}\right)$ corresponding to a $100 \%$ crystalline PP of $209 \mathrm{~J} / \mathrm{g}$ (Marinelli and Bretas 2003) All the data was statistically analyzed using SPSS v11 software.

\section{Gel Permeation Chromatography}

The TCB extracted PP from unweathered, outside and xenon-arc weathered WPC were analyzed at Equistar Chemicals Laboratory. The extracted PP were heated for $2 \mathrm{~h}$ at $175^{\circ} \mathrm{C}$ in TCB $(1-1,5 \mathrm{mg} /$ $\mathrm{mL})$ prior to injection $(300 \mu \mathrm{L})$. Analysis was performed on Waters GPC2000 system and separation was performed using two mixed-B columns (Polymer Labs) in series at $145^{\circ} \mathrm{C}$ and a TCB flow rate of $1 \mathrm{~mL} / \mathrm{min}$. The components were detected using refractive index, capillary viscometer, and Precision Detector LS systems. The GPC system was calibrated using a universal calibration curve (PS standard $\mathrm{K}=0,0001387 \mathrm{a}=0,70)$ with linear fit to determine the $M_{w}$ and $M_{n}$.

\section{RESULTS AND DISCUSSION}

\section{Flexural properties and water soak tests of unweathered WPC}

The MOR and MOE of the WPC were 28,9 $\pm 0,91 \mathrm{MPa}$ and 2,22 $\pm 0,10 \mathrm{GPa}$ respectively. The values were consistent with values for PP based WPC (Fabiyi et al. 2009). Water absorption and thickness swell of unweathered WPC are presented in figure 1. The results showed that both WA and TS were approximately $2 \%$ each after 1 day of water soak while WA and TS were approximately 14 and $8 \%$, respectively after 28 days of water soak. This trend was similar to other WPC (Bhaskar et al. 2012).

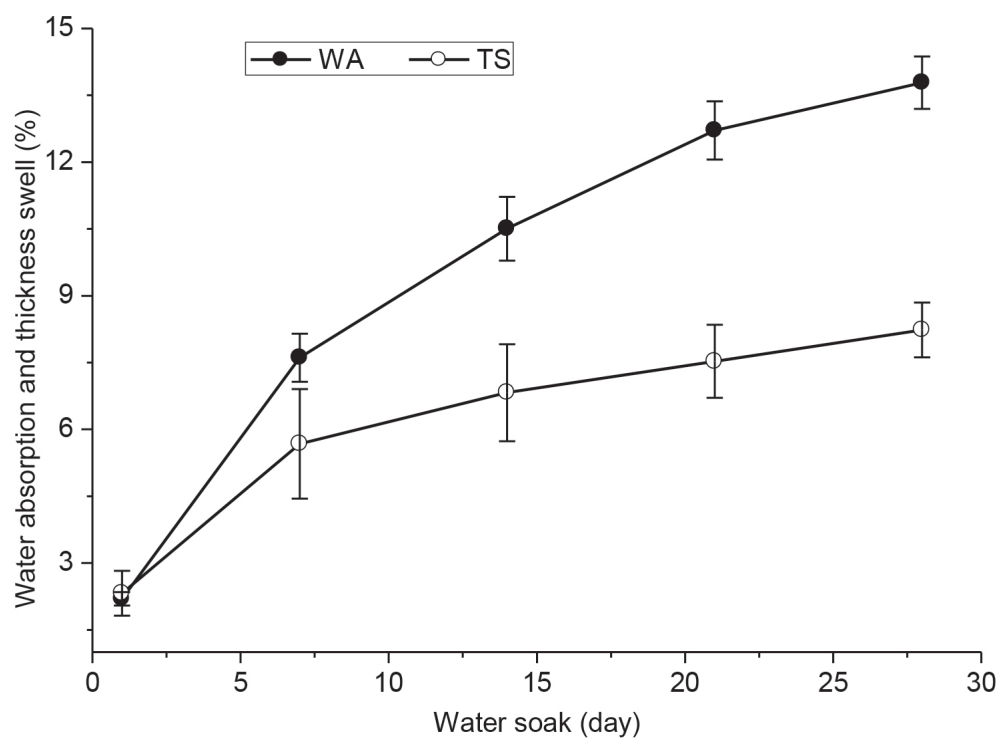

Figure 1. Water absorption (WA) and thickness swell (TS) of WPC. 


\section{Influence of weathering on polymer matrix physical morphology}

Figure 2 shows SEM of unweathered, 400, and $1200 \mathrm{~h}$ xenon-arc weathered WPC (SEM of the outside weathered WPC was not investigated). There were some observable cracks on the surface of weathered WPC, which are attributed to wetting and drying cycles between the surface and interior sections. Furthermore, moisture and temperature change could result in polymer chain-scission that normally causes highly crystallized polymer zones. Prolong weathering caused increase in wood degradation and erosion thereby leaving cracks and "pits" on the surface. Seldén et al. (2004) and Rabello and White (1997) made a similar observation. In addition, increase in weathering exposure period caused an increase in size and frequency of cavities on the surface (Figure 2).
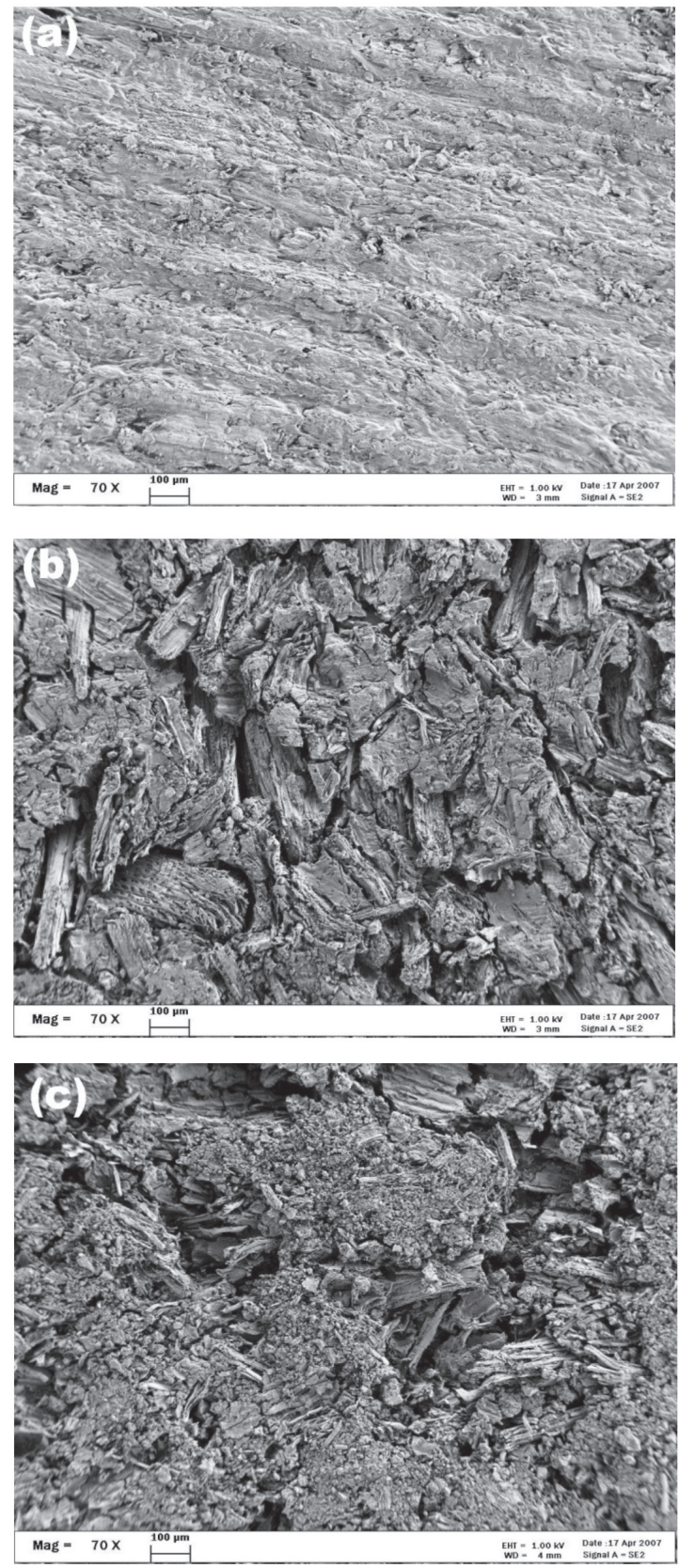

Figure 2. Scanning electron micrographs (70x) of (a) unweathered, (b) $400 \mathrm{~h}$ and (c) $1200 \mathrm{~h}$ xenon-arc weathered WPC. 


\section{Pyrolysis gas chromatography-mass spectrometry of WPC}

The chromatograms of the pyrolyzed unweathered and xenon-arc weathered WPC are shown in figure 3 (chromatograms of the outside weathered WPC are not shown). Molecular fragments from both wood and plastic were obtained from the pyrolyzed specimens (Fabiyi et al. 2008, Fabiyi and McDonald 2009). Semi-quantitative analysis was conducted based on the calibration technique employed. The wood content at the surface of unweathered and weathered WPC was accounted for by the total percentage area of all the identified wood derived compounds. The wood content at the WPC surface decreased upon xenon-arc and outside weathering from 60 to $41 \%$ and 60 to $45 \%$, respectively (Table 1). These results indicate that approximately 32 and $25 \%$ of the original wood content in the WPC was lost after 1200 $\mathrm{h}$ of xenon-arc and 120 days of outside weathering, respectively. Conversely, PP became conspicuous after the $1200 \mathrm{~h}$ xenon arc weathering on the chromatogram due to the degradation of the wood.
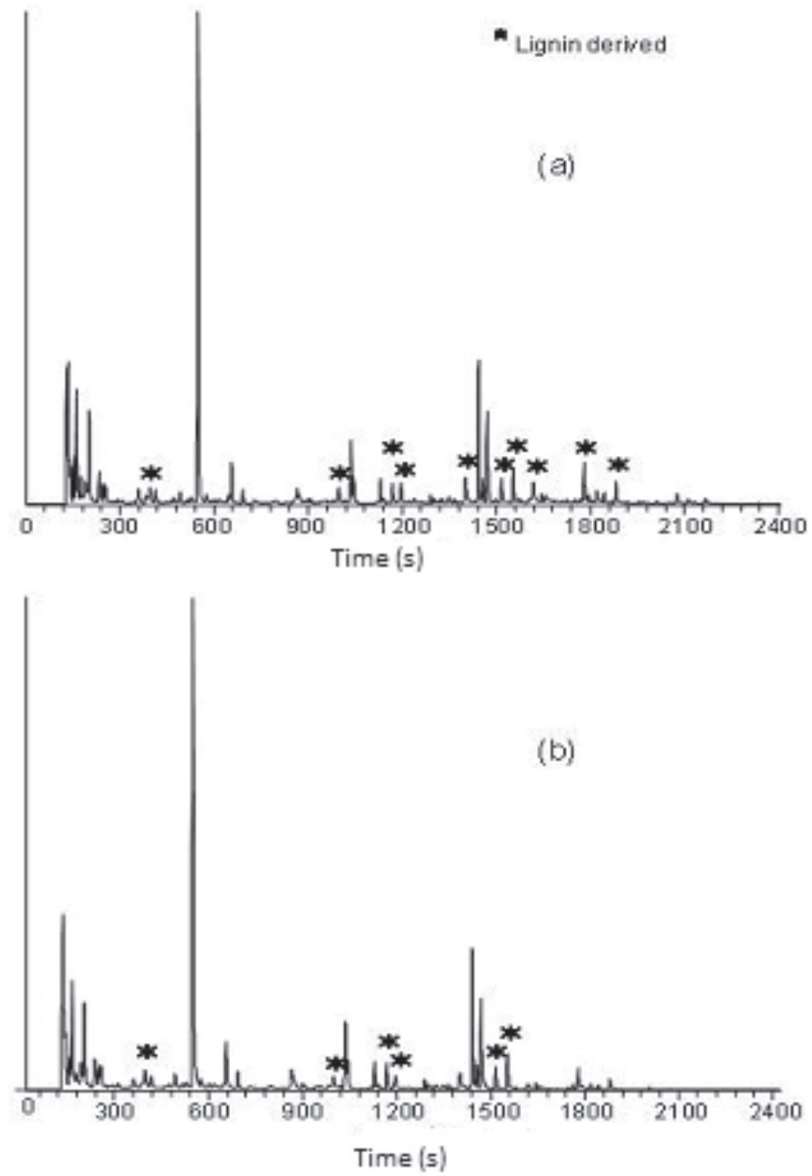

Figure 3. Pyrolysis total ion chromatograms of (a) unweathered and (b) $1200 \mathrm{~h}$ xenon-arc weathered WPC. 
Table 1. Effect of xenon-arc and outside weathering on wood content of WPC (number of observation, $\mathrm{n}=2$ ).

\begin{tabular}{cccc}
\hline \multicolumn{2}{c}{ Xenon-arc weathering } & \multicolumn{2}{c}{ Outside weathering } \\
\hline Exposure (h) & $\begin{array}{c}\text { Wood content } \\
(\%)\end{array}$ & $\begin{array}{c}\text { Exposure } \\
(\text { day })\end{array}$ & $\begin{array}{c}\text { Wood } \\
\text { content } \\
(\%)\end{array}$ \\
\hline 0 & $60 \pm 1,2$ & 0 & $60 \pm 1,2$ \\
50 & $58 \pm 1,5$ & 10 & $59 \pm 1,3$ \\
\hline 100 & $48 \pm 1,1$ & 30 & $54 \pm 0,9$ \\
150 & $45 \pm 1,1$ & 60 & $52 \pm 1,1$ \\
200 & $47 \pm 1,6$ & 90 & $45 \pm 1,3$ \\
400 & $45 \pm 1,0$ & 120 & $45 \pm 0,8$ \\
800 & $44 \pm 1,1$ & & \\
1200 & $41 \pm 1,6$ & & \\
\hline
\end{tabular}

\section{Molecular weight distribution}

GPC chromatograms of extracted PP from outside and xenon-arc weathered WPC are shown in figure 4. Differences occurred between the neat PP and extracted PP from the unweathered WPC (known as "composite matrix PP"). The composite matrix PP has a single broad peak, which is slightly higher in $M_{w}$ than that of neat PP. This suggests that the wood fiber exerts a stabilizing effect by slowing down the thermo-oxidation and degradation during processing. A further possible explanation of this stabilizing effect may be found considering also that wood contains a series of "extractives" (resins, tannins, polyphenols, waxes, terpenes, etc.) which could act as antioxidants and radical quenchers (Saito 1958a). Additionally, this broad peak in the composite matrix PP was higher in intensity than that of the neat PP. 

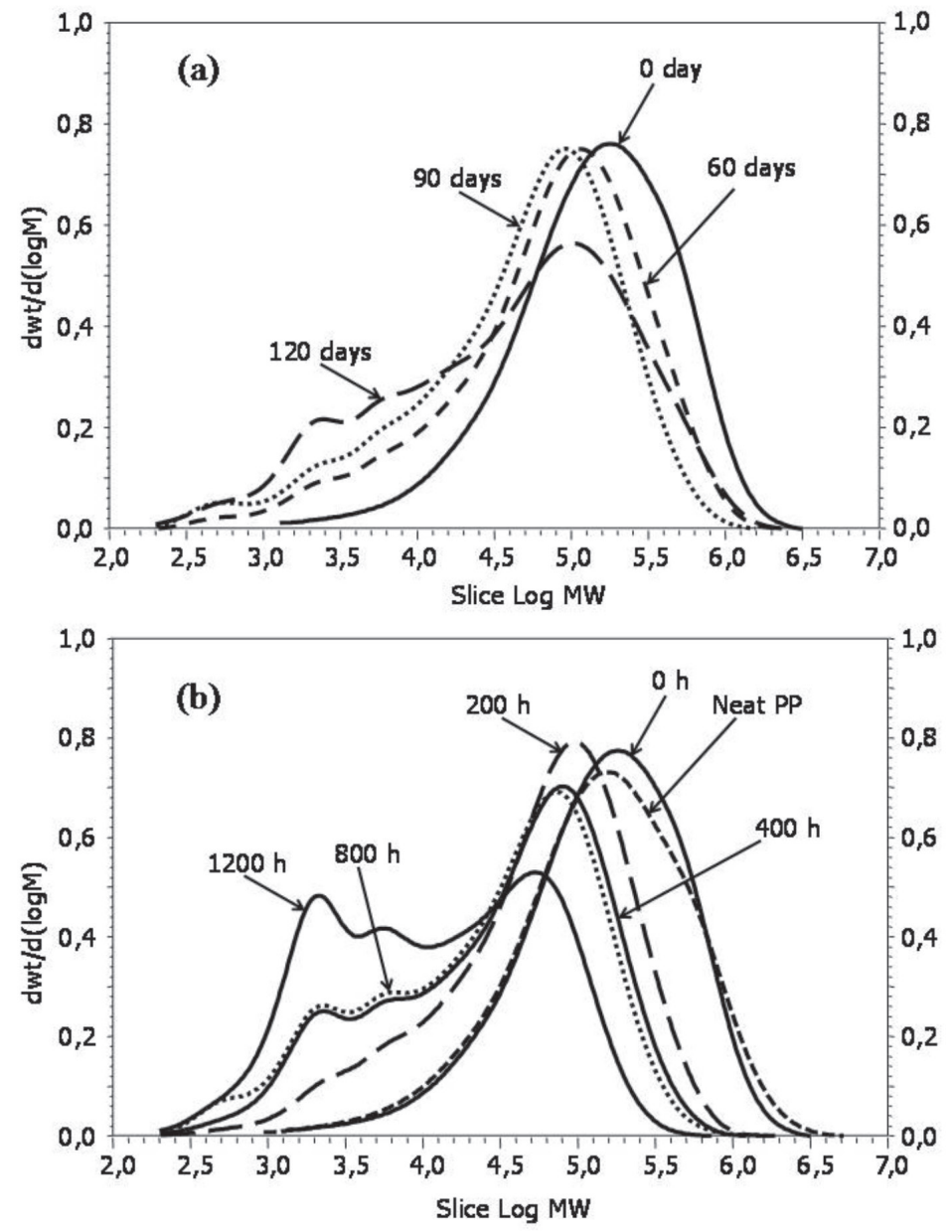

Figure 4. Gel permeation chromatograms of neat PP, extracted PP from unweathered and (a) outside and (b) xenon-arc weathered WPC.

The observed prominent peak appeared in all the weathered samples but decreased with prolonged exposure time; an indication of reduction of molecular weight upon weathering, which can consequently cause reduction in the mechanical properties of the WPC. Additionally, two other peaks emerged at the low molecular weight region from $200 \mathrm{~h}$ accelerated weathered WPC which became more conspicuous after $400 \mathrm{~h}$ of exposure. The $M_{w}$ and $M_{n}$ for unweathered and weathered extracted PP decreased with prolonged exposure time (Table 2). The trend or change in $M_{w}, M_{n}$ and polydispersity (PD) of the weathered PP gave insight into the types of reactions that took place during the WPC weathering. The increase in the PD with prolonged exposure time could only be due to the presence of a secondary cross-linking process (George et al. 2005). However, the decrease in the $M_{w}$ and $M_{n}$ of extracted PP show that a predominant chain scission process had taken place with increased exposure time (Table 2). Chiantore et al. (2001) reported that chain scission reactions have a direct influence on $M_{n}$, and that the number of apparent chain scissions per molecule, $N_{\text {scission }}$, can be estimated from the following relationship:

$$
N_{\text {scission }}=\frac{M_{n, 0}}{M_{n, t}}-1
$$

Where, $M_{n, 0}$ and $M_{n, t}$ are the number average molecular weights of the unweathered and at a given exposure time, respectively. 
Chain scission reactions can also be estimated and expressed in terms of the number of scission events per g of a material as given in equation (2) (Hoekstra et al. 1995):

$$
N_{t}=\frac{1}{M_{n, t}}-\frac{1}{M_{n, 0}}
$$

Table 2. Effect of xenon-arc and outside weathering on the molecular weight distributions of extracted PP in WPC

\begin{tabular}{ccccc}
\hline $\begin{array}{c}\text { Weathering } \\
\text { regime }\end{array}$ & $\begin{array}{c}\text { Exposure } \\
\text { time }\end{array}$ & $M_{w}(\mathrm{~g} / \mathrm{mol})$ & $M_{n}(\mathrm{~g} / \mathrm{mol})$ & $\begin{array}{c}\text { Polydis } \\
\text { persity } \\
(\mathrm{PD})\end{array}$ \\
\hline & 0 & 253200 & 54040 & 5 \\
& 200 & 106400 & 14010 & 8 \\
$\begin{array}{c}\text { Xenon-arc } \\
\text { (h) }\end{array}$ & 400 & 73050 & 7180 & 10 \\
& 800 & 64290 & 5660 & 11 \\
& 1200 & 34410 & 3800 & 9 \\
\hline & 0 & 253200 & 54040 & 5 \\
Outside & 60 & 146100 & 14580 & 10 \\
(days) & 90 & 125600 & 7020 & 18 \\
& 120 & 100200 & 8782 & 11 \\
\hline
\end{tabular}

The results obtained for the chain scissions are illustrated in figure 5. The number of chain scissions (both in scission $/ \mathrm{mol}$ and $\mathrm{mol} / \mathrm{g}$ ) that occurred in PP increased with longer exposure time of the WPC in both xenon-arc and outside weathering regimes. From figure 5, curvilinear relationship exists between number of scissions in the weathered PP and exposure time. Assuming that linear relationship that existed between the number of scissions and exposure time, it would have only been attributed to zero-order kinetics (Saito 1958b). However, in this study curvilinear relationship exists, therefore, it is suggested that stepwise degradation reaction occur in PP during WPC weathering. Consistent increase in the number of chain scissions that took place in PP throughout the duration of $1200 \mathrm{~h}$ and 120 days suggests that chain scission was more predominant than cross-linking reaction during WPC degradation. 


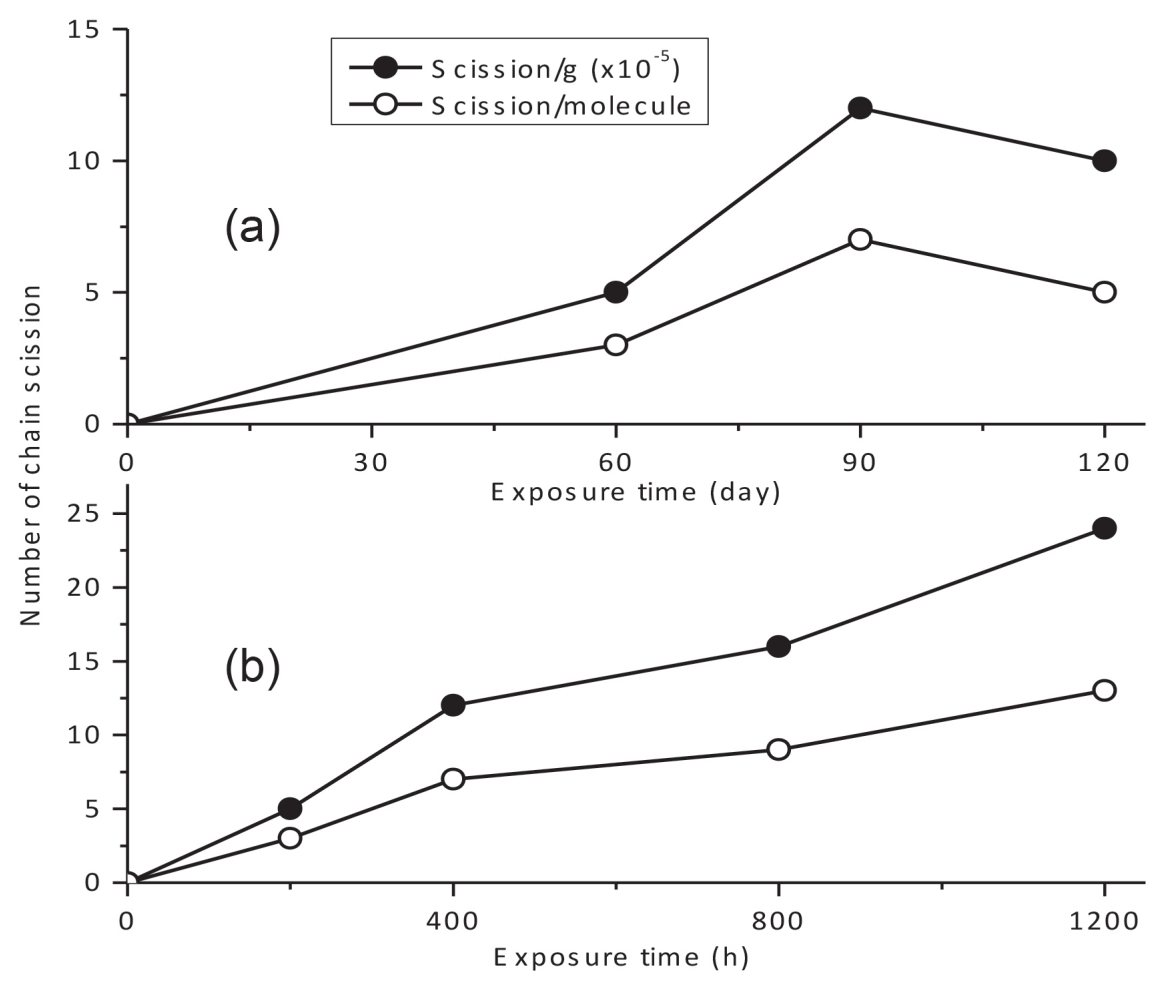

Figure 5. Apparent number of chain scissions in the oxidation reaction of extracted PP from outside (a) and xenon-arc (b) weathered WPC.

\section{Influence of weathering on polymer matrix crystallinity}

DSC was employed to determine the \% crystallinity of PP in weathered PP-based WPC. Figure 6 shows a DSC thermogram of extracted PP from the unweathered and xenon-arc weathered pine-based WPC (DSC thermogram of the outside weathered WPC is not shown). The transition temperatures on the curves are lower for the $1200 \mathrm{~h}$ accelerated weathered WPC than for the unweathered. The extracted PP experienced an increased in crystallinity during xenon-arc and outside weathering (Figure 7). These observations agree with the previous report on HDPE based WPC (Fabiyi and McDonald 2009). It was reported that weathering of HDPE resulted in an increase in polymer crystallinity (Jabarin and Lofgren 1994). Hulme et al. (2004) stated that UV degradation of PP involves chain scission leading to the formation of free radicals at the broken chain ends. Chain scission generation have higher mobility and can easily crystallize, resulting in an increase in crystallinity (Jabarin and Lofgren 1994). In general, the polymer chain alignability increases with shorter chains. Based on this, the increase in crystallinity of the extracted PP is due to the decrease in chain length (chain scission) caused by weathering as it enhance easy chain alignment. Stark and Matuana (2004) reported that polymer chain scission mostly caused reduction in the mechanical properties of WPC. An increased crystallinity could be caused by the changes in molecular weight which occurred as a result of polymer degradation leading to chain breaking and eventual secondary crystallization. 


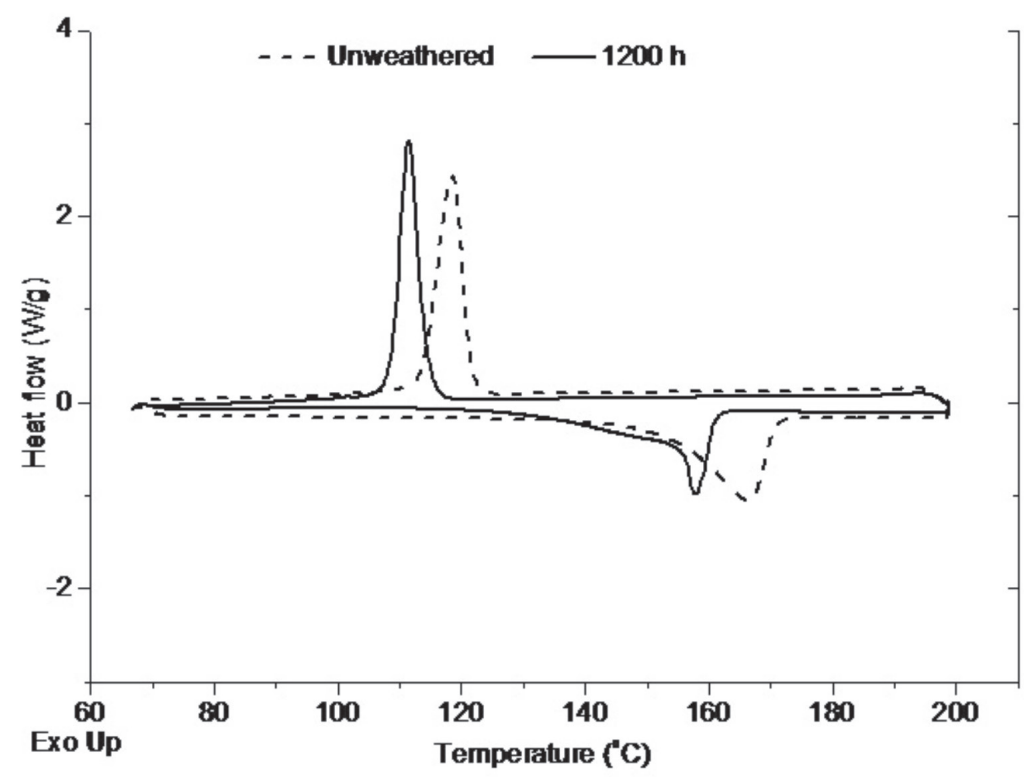

Figure 6. DSC thermograms of extracted polypropylene from unweathered and xenon-arc weathered pine based composites (bottom curves are from the heating cycle while the top curves are from the cooling cycle).

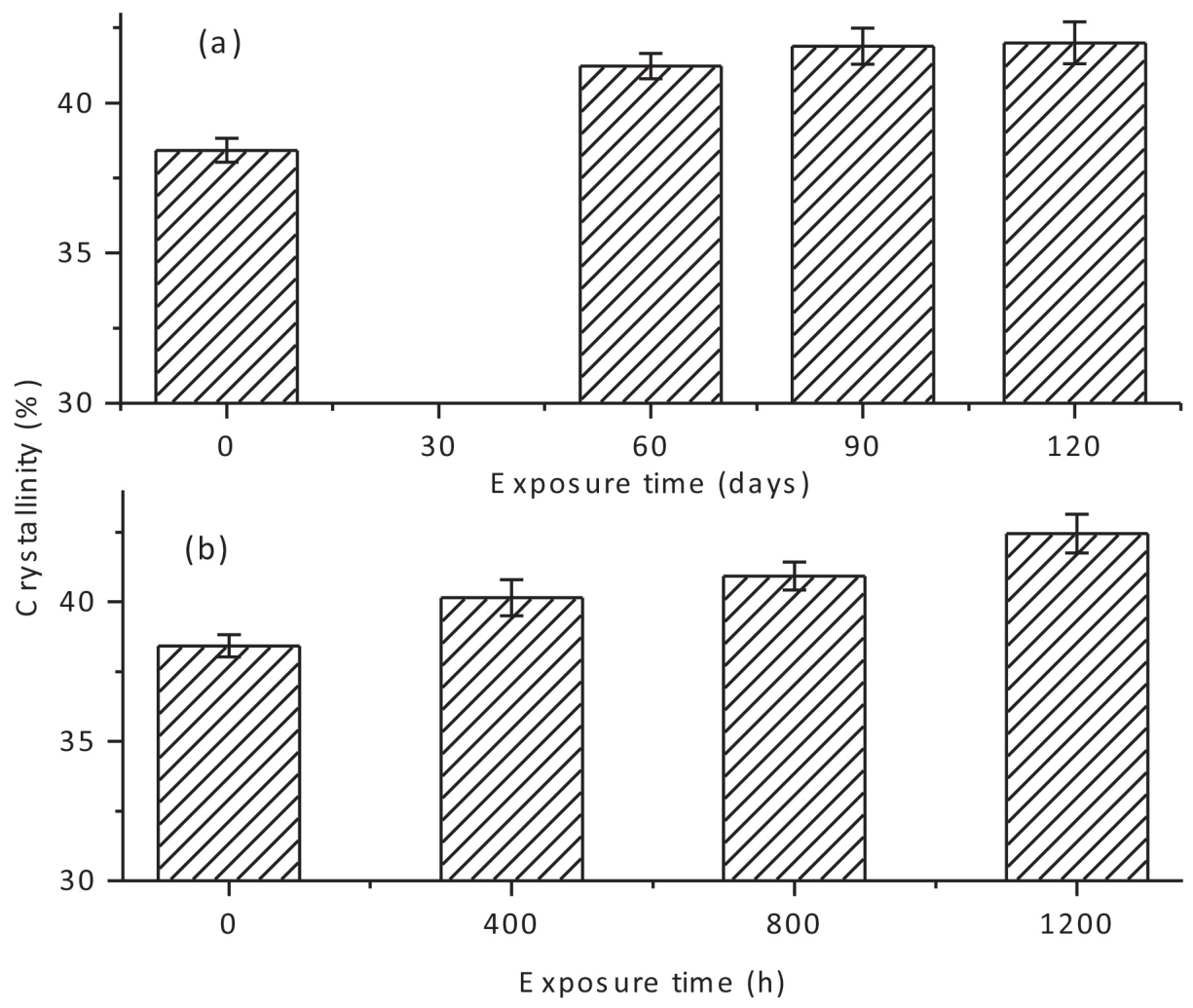

Figure 7. Effect of outside (a) and xenon-arc (b) weathering on the crystallinity of extracted PP from weathered pine based WPC. 
Establishing the relationship that exists between the increase in crystallinity and the decrease in $M_{w}$ (detail discussion on $M_{w}$ was already presented under the of the MWD results) extracted PP shows that correlation, $\mathrm{R}=0,90$ and 0,99 for xenon-arc and outside weathering, respectively exists; hence the decrease in $M_{w}$ is responsible for the increase in the crystallinity. The coefficient of determination $\left(\mathrm{R}^{2}=\right.$ 0,82 and 0,98 for xenon-arc and outside weathering, respectively) reveals that the trend of crystallinity change can be predicted using the changes in $M_{w}$. This finding agrees with a previous study on HDPE (Jabarin and Lofgren 1994) in that the reduction of $M_{w}$ of commercial HDPE increased the polymer chain mobility, thereby leading to a higher degree of crystallinity. Higher crystallinity results in a harder, more thermally stable but very brittle (loss of ductility) polymer (Jabarin and Lofgren 1994, Ehrenstein 2001).

\section{CONCLUSIONS}

This study investigated the performance of PP in weathered WPC. It was observed that wood degradation and erosion created cracks and "pits" at the surface; these increased upon prolonged weathering. In addition, wood erosion resulted in larger proportion of PP on the surface. Crystallinity of PP increased with an increase in weathering time. This could be due to easy and well aligned chains caused by the decrease in chain length (chain scission) upon WPC weathering. The $M_{n}$ and $M_{w}$ of PP decreased with increase in weathering period that will result in a reduction in the mechanical and rheological properties. An increase in the PD implies that a secondary cross-linking process occurred during weathering. In addition, a strong correlation exists between the percent crystallinity and the $M_{w}$. The practical implication is that recycling of weathered PP based WPC is possible but care should be taken to maintain WPC properties.

\section{ACKNOWLEDGMENT}

This work was supported by the USDA Forest Products Laboratory research project (grant number 05-JV-11111124-103). The authors acknowledge (i) the technical help of Drs. Michael Wolcott and Karl Englund at Washington State University and (ii) Gary Stark and Clay Enos for GPC analysis at the Equistar Chemical Company. 


\section{REFERENCES}

ASTM D 790-07. 2008. Standard test method for flexural properties of unreinforced and reinforced plastics and electrical insulating materials. West Conshohocken, PA. 08 (01):151-161.

ASTM D 570-98. 2005. Standard test method for water absorption of plastics. West Conshohocken, PA. 08 (01):35-37.

ASTM D 6662. 2003. Standard Specification for Polyolefin-Based Plastic Lumber Decking Boards.. West Conshohocken, PA. 08 (03):1035-1049.

ASTM D 1435. 2003. Standard Practice for Outdoor weathering of Plastics. West Conshohocken, PA. 08 (03):308-312.

ASTM D 3418. 1999. Standard Method for Transition Temperatures of Polymers by Differential Scanning Calorimetry.. ASTM Annual Book. Philadelphia, Pa. 8 (03):337-341.

Azuma, Y.; Takeda, H.; Watanabe, S.; Nakatani, H. 2009. Outdoor and accelerated weathering tests for polypropylene and polypropylene/talc composites: A comparative study of their weathering behavior. Polymer Degradation and Stability 94:2267-2274.

Bhaskar, J.; Haq, S.; Pandey, A. K.; Srivastava, N. 2012. Evaluation of properties of propylenepine wood Plastic composite. Journal of Materials and Environmental Science 3:605-612.

Chiantore, O.; Tripodi, S.; Sarmoria, C.; Valles, E. 2001. Mechanism and molecular weight model for thermal oxidation of linear ethylene-butene copolymer. Polymer 42:3981-3987.

Clemons, G. 2002. Wood-plastic composites in the United States. The interfacing of two industries. Forest Products Journal 52(6):10-18.

Ehrenstein, G. W. 2001. Polymeric materials: structure, properties, applications. Munich: Hanser Verlag. Germany. 277p.

Fabiyi, J.S.; McDonald, A.G.; Wolcott, M.P.; Griffith, P.R. 2008. Wood plastic composites weathering: Visual appearance and chemical change. Polymer Degradation and Stability 93: 1405-1414.

Fabiyi, J. S.; McDonald, A. G. 2009. Pyrolysis gas chromatography-mass spectrometry study of weathered wood plastic composites. In: Handbook on Mass Spectrometry Instrumentation, Ed. J. K. Lang, Nova Science Publishers, Inc.

Fabiyi, J. S.; McDonald, A. G.; McIlroy, D. 2009. Wood modification effects on weathering of HDPE-based wood plastic composites. Journal of Polymers and the Environment 17:34-48.

Fabiyi, J.S.; McDonald, A.G.; Morrell, J.J.; Freitag, C. 2011. Structural characterization of wood species on biodegradation of wood plastic composites. Composites part A 42: 501-510.

Falk, R. H.; Lundin, T.; Felton, C. 2000. The effects of weathering on wood-thermoplastic composites intended for outside applications. In Proceedings, Durability and Disaster Mitigation in Wood-Frame Housing; Madison, Wisconsin, pp. 175-179. 
George, B.; Suttie, E.; Merlin, A.; Deglise, X. 2005. Photodegradation and photostabilisation of wood - the state of the art. Polymer Degradation and Stability 88:268-274.

Hay, J. N. 1995. The physical ageing of amorphous and crystalline polymers. Pure and Applied Chemistry 67 (11): 1855-1858.

Hoekstra, H. D.; Spoormaker, J. L.; Breent, J.; Audouin, L.; Verdu, J. 1995. UV-exposure of stabilized and non-stabilized HDPE films: physico-chemical characterization. Polymer Degradation and Stability 49:251-262.

Hulme, A.; Williams, G.; Shipton, P; Philip, M. 2004. The vulnerability of polypropylene recyclate to photochemically triggered degradation. Published by The Waste and Resources Action Programme (WRAP), Banbury, Oxon OX16 0AH. United Kingdom. 113p.

Isasi, J. R.; Mandelkern, L.; Galante, M. A. J.; Alamo, R. G. 1999. The degree of crystallinity of monoclinic isotactic polypropylene. Journal of Polymer Science: Part B: Polymer Physics 37:323-334.

Jabarin, S. A.; Lofgren, E. A. 1994. Photo-oxidative effects on properties and structure of highdensity polyethylene. Journal of Applied Polymer Science 53 (4):411-423.

Klyosov, A. 2006. Oxidative Degradation and Lifetime of Composite Building Materials. In Proceeding of Progress in wood and bio-fibre plastic composites International Conference May 1-2, 2006, Toronto, Ontario, Canada.

Lundin, T. 2001. Effect of accelerated weathering on the physical and mechanical properties of natural-fiber thermoplastic composites. M.S. Thesis, Univ. of Wisconsin, Madison, WI.

Marinelli, A. L.; Bretas, R. E. S. 2003. Blends of polypropylene resins with a liquid crystalline polymer. I. Isothermal crystallization. Journal of Applied Polymer Science 87 (6):916-930.

Philip, M.; Attwood, J.; Hulme, A.; Williams, G.; Shipton, P. 2004. Evaluation of weathering in mixed polyethylene and polypropylene products. Published by The Waste and Resources Action Program. 113p.

Rabello, M. S.; White, J. R. 1997. Crystallization and melting behavior of photodegraded polypropylene - I. Chemi-crystallization. Polymer 38: 6379-6387.

Saito, O. 1958a. On the effect of high energy radiation to polymers. I. Cross-linking and degradation. Journal of the Physical Society of Japan 13 (2): 198-206.

Saito, O. 1958b. On the effect of high energy radiation to polymers. II. End-linking and gel fraction. Journal of the Physical Society of Japan 13 (12): 1451-1464.

Schauwecker, C.; Morrell, J.J.; McDonald, A.G.; Fabiyi, J.S. 2006. Degradation of a wood plastic composite exposed under tropical conditions. Forest Products Journal 56 (11-12): 123-129.

Selden, R.; Nystrom, B.; Langstrom, R. 2004. UV aging of PP/wood-fiber composites. Polymer Composite 25: 543-553.

Smith, P. M.; Wolcott, M.P. 2006. Opportunities for wood/natural fiber-plastic composites in residential and industrial applications. Forest Products Journal 56 (3): 4-11. 
Stark, N. M.; Matuana L. M.; Clemons, C. M. 2004. Effect of processing method on surface and weathering characteristics of wood-flour/HDPE composites. Journal of Applied Polymer Science 93 (3):1021-1030.

Stark, N. M.; Matuana L. M. 2004. Surface chemistry changes of weathered HDPE/wood-flour composites studied by XPS and FTIR spectroscopy. Degradation and Stability 86:1-9.

Torikai, A.; Shirakawa, H.; Nagaya, S.; Fueki, K. 1990. Photodegradation of polyethylene: Factors affecting photostability. Journal of Applied Polymer Science 40 (9-10): 1637-1646. 